\title{
POR SUA FAMÍLIA E PELO PROGRESSO DO BRASIL: O paradigma internacional de desenvolvimento da mulher e o discurso de gênero do governo Dilma
}

\author{
Thais de Bakker Castro ${ }^{1}$
}

\begin{abstract}
Resumo
A chegada de Dilma Rousseff à presidência do Brasil, em 2011, trouxe atenção renovada a temas relacionados a gênero, ecoando preocupações crescentes no cenário internacional sobre mulheres no desenvolvimento. No entanto, a violência contra mulheres e minorias sexuais continuou crescente no cenário nacional. A partir da análise de discurso de alguns pronunciamentos presidenciais, este trabalho busca compreender como o gênero foi (re)construído narrativamente no Brasil por esse governo e como isso se relaciona com interesses nacionais. Partindo de uma concepção performativa de gênero, retirada dos estudos de Judith Butler, entendemos o discurso como um elemento essencial para que as normas de gênero sejam (re)produzidas, e o papel de instituições como o Estado nesse processo é especialmente relevante, já que são imbuídas do poder regulatório responsável por conferir às normas de gênero caráter de legitimidade. Partimos da hipótese que a narrativa de gênero brasileira nos governos Dilma combinou elementos predominantes no paradigma internacional WID (Women in Development), o que refletiu preocupações econômicas brasileiras, com ideias sobre "natureza feminina" que refletem um contexto nacional que é também conservador.
\end{abstract}

Palavras-chave: Gênero e desenvolvimento; análise de discurso; mulheres no desenvolvimento; performatividade.

\section{Abstract}

When Dilma Rousseff was first elected the president of Brazil, in 2011, renewed attention was brought to gender issues, which also reflected a growing international interest in the issue of women in development. Despite that, violence against women and sexual minorities in the national scenario remained on the rise. Using discourse analysis, this work seeks to understand how gender was narratively (re)built in Brazil by this government and how this relates to national interests. Using a performative conception of gender, derived from Judith Butler's work, we understand discourse as a fundamental element for gender norms to be (re)produced, and the role of institutions such as the State as particularly relevant, since they hold the regulatory power responsible to confer legitimacy to gender norms. We defend the hypothesis that the Brazilian gender narrative in Dilma's government has combined elements predominant in the WID (Women in Development) international paradigm, which reflects brazilian economic preoccupations, with ideas about "feminine nature" that reflect a conservative national context.

Keywords:Gender and development; discourse analysis; women in development; performativity.

${ }^{1}$ É formada em Relações Internacionais pela PUC-Rio e atualmente bolsista Faperj Nota 10 de mestrado na mesma instituição. É também mestranda no Programa de Pós-graduação de Filosofia da UFRJ e tem como temas de estudo o Estado-nação e gênero.E-mail: thais.bakker@gmail.com 


\section{Introdução}

Quando confirmada candidata presidencial do PT em 2010, Dilma Rousseff disse em discurso que governaria como Lula, mas com "alma e coração de mulher". A partir disso, houve em seus mandatos uma preocupação inédita em apropriar "assuntos de mulheres" no discurso presidencial, o que pôde ser observado emdiversos pronunciamentos, em ocasiões como o dia das mulheres e uma Assembleia Geral da ONU. Basicamente, a ideia no cerne desse discurso é que Dilma representaria a consolidação do "avanço" na vidadas mulheres sendo a sua presença na presidência, como mulher, uma grande prova disso. Essa questão de gênero acabou sendo, então, um elemento central em seu governo.

Esse tipo de discurso que passou a aparecer com muito mais proeminência no governo Dilma ecoa, também, a crescente preocupação internacional com as mulheres, mais especificamente em relação aos processos de desenvolvimento. Desde meados dos anos 1970, a pauta de gênero dentro do desenvolvimento vem sendo cada vez mais introduzida na agenda de grandes instituições internacionais como a ONU e o Banco Mundial e, subsequentemente, trabalhada dentro de diversos países do Sul global, como o Brasil. Nesse âmbito, surge o termo women in development (mulheres no desenvolvimento, ao qual também se refere como WID) para designar iniciativas e ideias sobre desenvolvimento que têm como alvo a igualdade de gênero, através de certos pressupostos como a centralidade do trabalho. A abordagem WID acabou por ter muita aderência em grandes iniciativas e instituições, e cresceu bastante desde que começou a aparecer no cenário internacional.Contudo, esse paradigmavem também sendo alvo de diversas críticas, sobretudo no que tange seu caráter neoliberalista. A partir dessas críticas surge, em meados dos anos 1980, uma outra vertente que veio a ser apelidada de gender and development (gênero e desenvolvimento, ou GAD), e que trouxe como foco a necessidade de programas que sejam formulados de baixo para cima, e não de cima para baixo, entre outras questões.

A partir desse cenário, faremos uma análise do discurso de gênero do governo Dilma de forma a estabelecer quais concepções de gênero estão sendo passadas a frente. Buscamos, assim, uma melhor compreensão sobre o lugar do discurso brasileiro de gêneroem relação a um cenário mais amplo de crescente preocupação com essa questão, principalmente no âmbito do desenvolvimento internacional. Nossa hipótese é que o discurso do governo Dilma traz ainda fortes traços do paradigma WID, a despeito de essa abordagem ser alvo de cada vez 
mais críticas.A escolha de nosso objeto - discursos sobre gênero e desenvolvimento - se dá justamente porque a maior parte dos discursos sobre gênero do Estado brasileiro, dentro do recorte temporal selecionado, vieram atrelados a preocupações com o desenvolvimento do país, refletindo debates que perpassam grandes organizações, instituições e agências do cenário internacional; e a escolha do recorte temporal do governo Dilma se dá devido à forte apropriação de assuntos de gênero no discurso presidencial em ambos os mandatos.

Encontramos elementos do paradigma WID no discurso de Dilma especialmente no que diz respeito ao papel das mulheres na economia. No discurso do governo Dilma, assim como no paradigma WID, as mulheres são essenciais para que a nação vá para a frente, e por isso o país investe para que trabalhem; são seres humanos, e por isso precisam ser reconhecidas como tal. Ao mesmo tempo, também encontramos no discurso de Dilma elementos conservadores, que se mostram por vezes contraditórios, demarcando na mulher uma determinada natureza que a define e limita. "A mulher" se torna símbolo de mãe, cuidadora, pilar familiar e também de seu país: "cada casa brasileira, e cada empresa deste país, mostram o que cada mulher é capaz de fazer por sua família e pelo progresso do Brasil" (ROUSSEFF, 2014). O país é análogo ao lar, do qual a mulher tem papel de cuidar e vem tendo as condições de fazê-lo graças às iniciativas para o desenvolvimento. Vemos uma mulher que tem o papel de nutrir ambos a nação e seus filhos, que precisa trabalhar para o progresso, mas também cuidar da família para seu crescimento. Essa mulher tem o dever de ir para frente, mas também de permanecer onde está.

Este trabalho partirá das definições de gênero de Judith Butler (1998; 1999; 2004), que o entende como conjuntos de discursos e atos performativos que variam através do tempo e do espaço, mas que passam a ser entendidos como naturais através da repetição. Assim, não existe uma natureza da mulher, mas apenas um conceito de mulher que vai se passando como verdadeiro e natural conforme é repetido incessantemente, de forma a cristalizar normas hegemônicas.Nesse sentido, tentaremos nos encaixar dentro do corpo da teoria Queer nas Relações Internacionais. Orientado em grande parte pela linguagem, esse corpo teórico busca justamente evidenciar relações de dominação e hierarquias de gênero e sexualidade nas estruturas políticas e sociais (o nome "Queer" vem de um termo do inglês que designava estranheza e que, mais tarde, veio a ser apropriado por movimentos LGBT, dentre outras coisas como símbolo de luta, e posteriormente deu nome à vertente teórica que busca uma visão crítica sobre gênero e sexualidade na sociedade). 
A partir disso, tentaremos apontar, nos discursos sobre gênero e desenvolvimento do Estado brasileiro sob a gestão Dilma (que se localizam dentro de um universo mais amplo de paradigmas sobre gênero e desenvolvimento propagados no âmbito internacional) espaços onde hierarquias e normas de gênero sejam contestadas ou perpetuadas. O Estado brasileiro, por ser um local de legitimidade e uma instituição que formula discursos políticos e jurídicos, é compreendido aqui como um ator com poder de realizar a manutenção de hierarquias e normas de gênero, de onde parte sua relevância como centro de nossa análise. Devido também ao nosso foco no papel do discurso, nos utilizaremos da metodologia da análise de discurso como forma de evidenciar normas e hierarquias.

Este trabalho será estruturado da seguinte forma: a primeira seção abordará questões metodológicas e a base teórica sobre a qual nosso trabalho irá se amparar, falando sobre os pontos da teoria de gênero de Judith Butler que mais serão relevantes; a segunda abordará brevemente o contexto global sobre gênero e desenvolvimento, para que possamos localizar o discurso brasileiro em relação a um cenário mais amplo; a terceira seção terá como foco uma análise das definições de mulher passadas a frente pelo discurso brasileiro; e a quarta analisará os discursos acerca do lugar dessa mulher no mundo.

\section{O Gênero, a Política eos Discursos}

Sublinhando as hierarquias reproduzidas pelo discurso, que serão exploradas neste trabalho, estão as noções preliminares de sexo, gênero e sexualidade. Esses são elementos profundamente conectados: tipicamente compreende-se que existem dois sexos, feminino e masculino, que se manifestam na espécie humana como um de dois gêneros, homem ou mulher, de quem se presumirá heterossexualidade.Ao se pensar em gênero no sentido performativo - que será utilizado aqui - "mulher (assim como "homem"), não é tanto um sujeito ontologicamente independente quanto um ideal imaginado pela coletividade social, infligido sobre, mas ao mesmo tempo buscado porboa parte dos seres humanos. É uma construção imposta e reforçada a todo momento através de diversas instâncias de discurso, e a todo tempo se busca cumpri-la, voluntaria ou involuntariamente.

"Mulher" passa a existir apenas através da repetição incessante de umdiscurso, que inclui também a forma como as pessoas se apresentam para o mundo - suas performances. A ideia de uma mulher que, por ser mulher, é definida por elementos específicos (como, por 
exemplo, a forma que fala e se veste, ou atributos que possui, como um "lado emocional" mais forte) é reproduzida nas performances, nos corpos, reforçando ainda mais a força do construto "mulher" em um ciclo que se retroalimenta a todo o tempo. Assim, essas ideias sobre homem e mulher formam também o entendimento das pessoas sobre corpos, constituindo uma ontologia do corpo humano onde "mulher" e "homem" são compreendidos como objetos de existência completamente independente de atos individuais, como consequências inevitáveis de determinada estrutura biológica, como coisas naturais.

Devido à importância da linguagem na consolidação do gênero (e todos os seus predicados, incluindo sexo e sexualidade), uma das ferramentas mais adequadas a estudos de gênero que se enquadrem no espectro Queer (que busca analisar o papel do gênero na estruturação da sociedade e da política através do conceito de gênero performativo) é a análise de discurso. A análise de discurso surge como uma ferramenta que propicia entendimento sobre as formas através das quais as normas de gênero são construídas na sociedade, sobre como exatamente o sujeito do gênero é circunscrito e quem fica do lado de fora dessa circunscrição. Se "mulher" e "homem" são ficções materializadas através da repetição incessante de determinado discurso, para transcender as limitações de tal binário é necessário primeiramente compreender onde e como este se reproduz na linguagem.

Os corpos são "constrangidos e controlados por discursos morais repressivos emanando de instituições políticas, econômicas e judiciais de autoridade social" (GRIFFIN, 2009: 37, tradução nossa). A partir disso, a categoria "mulher" é "produzida e restringida pelas próprias estruturas de poder através das quais a emancipação é buscada" (BUTLER, 1990: 4, tradução nossa). Quando as performances inteligíveis de gênero, heteronormativas, de homem e mulher, são reproduzidas no âmbito de instituições de autoridade, é reforçada a suposta obrigatoriedade de certos pressupostos de gênero (por exemplo, mulheres como mães), e é estimulada a rejeição a tudo que não se encaixa no sujeito da política.

As normas sociais, responsáveis por regular o gênero, são também responsáveis por determinar quem é humano; são elas que permitem às pessoas "respirar, desejar, amar, e viver, e são essas normas e convenções que restringem ou evisceram as condições da vida" (BUTLER, 2004: 8, tradução nossa). O custo das normas é o de relegar algumas pessoas à categoria de sub-humanas, ao circunscrever aquilo que é humano, quem é o sujeito legítimo da lei. É a partir disso que surge a ideia de abjeção, de corpos que se tornam abjetos quando não são mais compreensíveis como humanos "normais". Quando internalizamos que existem 
apenas dois gêneros, e que eles são definidos pelos atributos $\mathrm{x}$ ou $\mathrm{y}$, esses dois se tornam os únicos dois gêneros inteligíveis - enxergamos corpos e tentamos automaticamente encaixá-los nessas atribuições anteriores. Tudo aquilo que não conseguirmos facilmente encaixar em nenhum dos dois se torna abjeto (como é o caso de pessoas transexuais), e aquilo que é abjeto se torna alvo de um desejo de correção ou apagamento, o que dá origem à violência.

Nesse sentido, a construção de "mulher" como sujeito da política - como nas práticas discursivas que serão analisadas neste trabalho - é uma questão delicada e muitas vezes está diretamente conectada a certas formas de violência de gênero. Em uma simplificação grosseira, podemos dizer que quando se constrói como sujeito do discurso político sobre gênero a "mulher" que é mãe, por exemplo, isso implica em reforçar a associação compulsória de mulheres à maternidade, de forma que o desvio à maternidade se torna mais difícil, bem como (ainda) passível de correção. Da mesma forma, quando se reforça em atos políticos uma imagem de mulher que é invariavelmente heterossexual, isso implica em reforçar o caráter abjeto da mulher que é lésbicalbissexual. Quando se reforça em infinitas instâncias que políticas de gênero são úteis para representar mulheres, que por sua vez são mães, heterossexuais e de sexo feminino, isso implica em aprofundar a rejeição às performances de gênero marginais. E essa rejeição se manifesta através de tentativas de exclusão ou normatização, levadas a cabo através das mais diversas formas de violência física ou moral:

Esse imperativo, essa prescrição, requer e institui um "lado de fora constitutivo" - o indizível, inviável, "não-narrativizável" que assegura e, a partir daí, falha assegurar as próprias fronteiras da materialidade. A força normativa da performatividade - seu poder de estabelecer o que se qualifica como "ser" funciona não apenas através da reiteração, mas através de exclusão também. E no caso de corpos, essas exclusões assombram a significação como suas fronteiras abjetas ou como aquilo que é estritamente excluído: o não "vivível", o não"narratizável”, o traumático (Butler, 2004, p.188, tradução nossa).

Este trabalho faz parte de um conjunto de esforços que não visa simples constatações analíticas, mas simuma crítica às construções normativas de gênero motivada pelo desejo de mudança, como vem sendo feito na teoria Queer. Dentro das RI encontramos esforços parecidos nos trabalhos de teóricas como Spike Peterson (1999), por exemplo, que busca localizar os estereótipos de gênero incutidos dentro de fenômenos como o nacionalismo, de modo a evidenciar uma relação co-constitutiva entre esses dois fenômenos que acaba por gerar opressão.No sentido de somar a esforços críticos, a teoria de Butler é interessante por, dentre outras coisas, introduzir a possibilidade de desmantelar o gênero como o conhecemos. 
Butler chama gênero de uma "repetição estilizada de atos através do tempo" (BUTLER, 1988: 519, tradução nossa) e coloca que, se assim o for, "então as possibilidades de transformação do gênero se encontram na relação arbitrária entre tais atos, na possibilidade de um tipo diferente de repetição, na quebra ou na repetição subversiva daquele estilo" (BUTLER, 1988: 520, tradução nossa).

Mais ainda, identidade de gênero é um feito performativo "compelido por sanções sociais e tabu. Em seu próprio caráter performativo que reside a possibilidade de contestar seu status reificado" (BUTLER, 1988: 520, tradução nossa). Através dessa concepção de gênero, o discurso passa a ser uma ferramenta poderosa a ser usada também no desmantelamento da opressão proveniente de imposições sociais dos estereótipos binários e heterossexuais de "homem" e "mulher" - e esse insight é especialmente relevante em trabalhos dedicados à aplicação da teoria Queer em objetos políticos, como é o caso de boa parte dos estudos Queer nas Relações Internacionais.

Assim, analisamos o discurso do Estado brasileiro (sob a gestão Dilma) por essa ser uma instância que, devido a seu poder, tem papel importante na consolidação das normas de gênero, concedendo a elas um caráter de legitimidade. Enxergamos no discurso um papel fundamental na estruturação da sociedade relativamente ao gênero; na determinação de como as mulheres serão tratadas, e quais lugares ocuparão. No entanto, também enxergamos no discurso um potencial subversor, justamente porque o gênero não é imutável nem natural, mas contingente. Tentaremos analisar de quais formas o discurso brasileiro sobre gênero foi utilizado na gestão Dilma, e quais os impactos disso.

\section{A Questão do Gênero e o Desenvolvimento Internacional}

O interesse do governo Dilmaem gênero (bem como o fato dessa questão aparecer frequentemente ao ladoda questão do desenvolvimento) não acontece no vácuo. Os discursos sobre gênero e desenvolvimento, sejam vindos de agências internacionais ou de governos nacionais, encontram grande influência em certos paradigmas predominantes no cenário internacional. A consideração do gênero como elemento relevante nos processos de desenvolvimento data dos anos 1970, onde se encontram as raízes da abordagem women in development, que defendia a inserção de mulheres no desenvolvimento. Desde então vêm acontecendo inúmeros debates acerca da melhor forma de entender e aplicar gênero como 
uma variável que influencia e é influenciada pelo desenvolvimento. Nesse contexto, surge outra importante abordagem, gender and development (gênero e desenvolvimento). Esses termos funcionam como sínteses de ideias mais amplas e acabam por ser aplicados como diretrizes tanto para a formulação de políticas de desenvolvimento, como para os posicionamentos discursivos que sublinham essas iniciativas - sendo o discurso e a política elementos interconectados, como brevemente discutido na seção anterior.

As décadas de 1960 e 1970 viveram um florescimento de movimentos feministas no Norte, especialmente nos Estados Unidos. Paralelamente e talvez mesmo por decorrência disso, as questões de gênero, sob a forma de questões de mulheres, foram conquistando cada vez mais espaço nas pautas da Organização das Nações Unidas. Ao passo que a necessidade de assegurar os direitos das mulheres como direitos humanos já vinha sendo afirmada no âmbito da ONU desde 1947, a década de 1970 trouxe também atenção para a questão das mulheres com relação aos processos de desenvolvimento.

Foi decidido que 1975 seria o Ano Internacional das Mulheres, quando aconteceu a Primeira Conferência Mundial sobre as Mulheres, no México - que por sua vez declarou o período de 1976 a 1985 como a UN Decade for the Advancement of Women (a década ONU para o avanço das mulheres). A ONU declarou que, dentro desse período, o "avanço" das mulheres seria pauta prioritária para governos nacionais e agências de desenvolvimento - e foi nesse âmbito que o conceito de women in development (mulheres no desenvolvimento) começou a ganhar força no cenário internacional, onde ainda se encontra presente em muito do discurso das grandes organizações e agências envolvidas em desenvolvimento, como o Banco Mundial, segmentos da ONU, USAID etc., além de muitas diretrizes de governos nacionais.

O paradigma WID defende demandas retiradas, em grande medida, do feminismo liberal e que pressupõem a aplicabilidade universal de modelos Ocidentais. O objetivo central se trata da inclusão de mulheres dentro de processos de desenvolvimento já existentes, se encaixando dentro do framework neoliberal (O'BRIEN et al, 2003: 35). As defensoras dessa perspectiva argumentam em favor da necessidade de que hajam pesquisas e estatísticas específicas sobre a condição das mulheres, com o objetivo final de que elas sejam integradas adequadamente ao desenvolvimento de seus respectivos países, tendo acesso tanto a necessidades básicas quanto a empregos, propriedades e participação na economia. 
A abordagem WID mira napromoção de igualdade entre mulheres e homens no sistema vigente - aspecto que herda da vertente liberal do feminismo. O feminismo liberal, por sua vez, se ampara em uma ideia fundamentalmente humanista. Martha Nussbaum, feminista liberal que fala sobre desenvolvimento, declara que "nós deveríamos de fato começar com uma concepção do ser humano e da funcionalidade humana ao pensar na igualdade das mulheres em países em desenvolvimento" (NUSSBAUM, 1995: 62, tradução nossa). Assim, conforme apontado por Vivianne Jabri:

A chamada por igualdade é, portanto, baseada em uma concepção universalista de agência, que vê agência como sendo situada na racionalidade do Eu. O momento formativo dessa visão distintamente modernista é que mulheres, através de significativas divisas culturais e sociais, partilham de uma agenda comum, independentemente das particularidades que definem suas experiências e de suas diferentes localizações com relação a estruturas de significação e dominação (JABRI, 2004: 272, tradução nossa).

O resultado disso é que existe a pressuposição de algo, uma racionalidade essencial, que seria comum a todas as pessoas, inclusive mulheres - que partilhariam, portanto, também dos mesmos objetivos, como por exemplo a obtenção de empregos na economia formal. Esse essencialismo de gênero é também responsável pela cristalização do entendimento de mulher, ao delinear determinados atributos como sendo fundamentais à própria existência de mulheres, como se o gênero fosse um fenômeno natural. Ademais, existe por trás das aspirações da vertente WID a ideia de "avanço" (como diz o próprio nome da Década para o Avanço das Mulheres). As agências trabalhando dentro do paradigma WID "continuavam trabalhando dentro do paradigma de modernização. Ou seja, presumiam que desenvolvimento era medido pela adoção de tecnologias, instituições e valores Ocidentais" (PAPARTet al, 2000: 57, tradução nossa).

Tal avanço seria, portanto, um passo à frente em uma caminhada linear em direção aos objetivos finais do projeto neoliberal de desenvolvimento, ou seja, o bem-estar social decorrente da aplicação universal bem-sucedida do modelo político-econômico Ocidental. O "avanço" das mulheres seria a aproximação delas de seus objetivos finais de bem-estar, os quais elas supostamente teriam todas em comum, e que seriam todos relativos à sua ampla inserção em ideais Ocidentais.

No âmbito dessa crítica, surge como alternativa a vertenteGender and Development (gênero e desenvolvimento). A mais básica diferença dessa abordagem com relação àWID é que o foco sai de mulheres como indivíduos para relações de gênero que geram desigualdades em processos de desenvolvimento. Inaugura-se o paradigma GAD como resultado dos 
esforços de mulheres, predominantemente da sociedade civil e de países de "Terceiro Mundo", motivadas por ideais anti-capitalistas.

A implicação do foco no gênero, em oposição à mulher, é que a tal "substância" comum que constitui mulheres (da qual se fala na seção anterior) deixa de ser um elemento presente. Isso, em si, é uma reivindicação de poder de fala - passa a ser possível afirmar que mulheres no "Terceiro Mundo" podem não partilhar dos mesmos objetivos da maior parte das mulheres do Norte, bem como não se entendem da mesma forma, já que seu contexto muitas vezes é bastante diferente. A chamada principal é por uma forma de pensar desenvolvimento que se preocupe com particularidades locais, deixando de tentar aplicar uma fórmula universalista motivada por ideais modernizadores e não mais pressupondo uma unidade presente no gênero feminino. Cultura não mais é um elemento que se sobrepõe à racionalidade do Eu, esta por sua vez universal.

Sobre os programas para desenvolvimento empregados com base na perspectiva WID, uma das principais problemáticas apresentadas, e que coloca a perspectiva GAD como contraponto alternativo, é que: “a pressuposição implícita por trás de muitos desses programas era que o principal problema das mulheres no Terceiro Mundo era insuficiente participação em um processo de crescimento e desenvolvimento que, fora isso, era benéfico" (SEN \& GROWN, 1987: 15).

Assim, temos um panorama global de crescente valorização de mulheres em processos de desenvolvimento. Observamos cada vez mais iniciativas nesse sentido, por parte de diversas grandes organizações mundiais. Não à toa, partes desses discursos são ecoados em países como o Brasil. O cerne desses esforços continua sendo influenciado pelo paradigma WID, derivado de demandas do feminismo liberal e de concepções humanistas; mas estas não são universalmente aceitas dentro dos feminismos e encontram resistência em paradigmas alternativos como o GAD, que transfere o foco do individual para o sistêmico, buscando uma inclusão que vem de baixo para cima, e não vice-versa.

Ambas as abordagens continuam se utilizando do sujeito mulher (incluindo aí todas as demarcações discursivas do que constitui uma mulher) como alvo de suas políticas. No entanto, o conceito de gênero introduzido pela perspectiva GAD, diferentemente da WID, vai na direção contrária à crença em uma "substância" comum entre todas as mulheres, que é por sua vez baseada em ideias Ocidentais e neoliberais sobre interesses e necessidades de mulheres. Se mulheres possuem particularidades, então não existe uma "mulher" universal - 
são construtos flutuantes com relação a espaço e tempo. O foco deixa de ser em "mulher", mas em "mulheres" e suas necessidades específicas.Tendo elucidado esse contexto, seguiremos para as próximas seções, que buscarão localizar o discurso brasileiro também em relação ao cenário internacional.

\section{Quem éa Mulher Brasileira?}

Começaremos nossa análisefalando sobre algumas das bases que permeiam a própria concepção de gênero que permeiam as políticas de desenvolvimento em relação a mulheres. $\mathrm{O}$ discurso de dia da mulher de 2012é aberto com: “Hoje, Dia Internacional da Mulher, é uma data ideal para uma presidenta falar com suas irmãs brasileiras, de coração aberto, de mulher para mulher" (ROUSSEFF, 2012). A ideia que sublinha esta, como outras evocações a uma suposta comunidade entre a presidenta que fala e as cidadãs que a escutam, é que mulheres partilham de algo em comum.

A narrativa desse pronunciamento, povoada por "nós mulheres" e "minhas irmãs" se ampara na ideia de um sentimento de comunidade que existe entre quem fala e quem escuta, motivado, em primeiro lugar, por serem brasileiras; em segundo lugar, por serem mulheres. Assim, partilhariam de determinadas experiências que permitiriam identificação e um discurso que use "nós" em vez de "você", ou que refira a totais desconhecidas como "irmãs". $\mathrm{O}$ que, exatamente, essas mulheres possuiriam em comum de forma a permitir identificação será discutido na próxima seção.Da mesma forma, repetidamente se usa a expressão "a mulher" - refletindo justamente a ideia de uma essência comum a constituir $a$ mulher como sujeito único, ponto que acaba por ecoar a abordagem WID.

$\mathrm{Na}$ primeiraseção, falamos sobre "a mulher" como sujeito da política e as problemáticas levantadas por Judith Butler acerca disso (BUTLER, 1999). A questão é que, para que "a mulher" seja construída como sujeito da política ou da lei é preciso que se defina o que constitui uma mulher. Essa definição implica diretamente na construção daquilo que se compreende por uma mulher "de verdade", ajudando, dessa forma, a reforçar comportamentos que serão ou não aceitáveis, que serão ou não compreendidos pela lei, que garantirão ou não salvaguardas, que permitirão ou não que determinadas mulheres sejam compreendidas como cidadãs, como boas nacionais, como humanas. 
Mas o que, exatamente, caracteriza uma mulher? Encontramos diversas instâncias no pronunciamento de dia das mulheres de 2012 que nos apontam para a resposta para essa pergunta. Este é o primeiro trecho relevante:

O pior é que, em certas circunstâncias, a mulher continua sendo a mais pobre dos pobres, a mais sofredora entre os sofredores. Mas até aí nos surpreende a força da mulher, porque mesmo quando está em uma dura condição de pobreza, a mulher é a principal mola de propulsão para vencer a miséria. Sabe por quê? Porque ela é o centro da família. Porque quando uma mulher se ergue, nunca se ergue sozinha, ela levanta junto seu companheiro, ela levanta junto seus filhos, ela fortalece toda a família (Rousseff, 2012).

Então, sobre "a mulher", sujeito ao qual o discurso se refere, sabemos: 1- que sua imagem é associada àquela de uma família; 2- que nesta família, ela tem um papel específico, de mola propulsora, de centro e de elemento que dá força aos outros; 3 - sabemos também que é heterossexual, já que tem um companheiro; e 4- sabemos que é mãe, já que tem filhos. "A mulher" é indissociável do âmbito doméstico: ainda que deva trabalhar fora e trabalhe, ainda que contribua com a política e com a nação, "a mulher" ainda é, por excelência, responsável pela esfera doméstica da vida, responsável pelo lar, responsável pela família nuclear que é a base da sociedade e da cidadania.

O segundo trecho que destacaremos é: “A mulher é, por natureza, fonte de vida e de energia" (ROUSSEFF, 2012). A ideia da mulher que é fonte de vida diz respeito diretamente a seu papel como mãe; como escrevemos na seção anterior, a expressão "a mulher" diz respeito a uma essência que todas as mulheres possuiriam em comum, e "fonte de vida e energia" nos diz que essa essência é composta, também, pela maternidade. E essa maternidade funciona de uma forma específica, que podemos observar no trecho anterior: a mãe é heterossexual, é forte, possui um companheiro que é homem.A expressão "por natureza" nos leva a uma outra questão. Esta evoca diretamente a imagem do gênero que é incontestável: ele vem da natureza. É, assim, conectado a uma estrutura biológica e também é independente de ações individuais. Este é um exemplo das construções discursivas às quais nos referimos no primeiro capítulo, que constroem o gênero como um elemento anistórico, universal e natural. Um predicado comum às mulheres é a maternidade, e isso é determinado pela natureza, já que o gênero é algo que simplesmente é, independente da nossa voluntariedade.

Ainda sobre a "natureza" da mulher, desviaremos para o pronunciamento no Fórum de Mulheres Líderes sobre gênero no desenvolvimento sustentável, onde encontramos a mesma construção de uma suposta natureza feminina: 
As mulheres, como geradoras de vida, ocupam, em todas as sociedades humanas, um papel especial, e devemos, por isso, reconhecer este papel, tanto do ponto de vista da proteção ao meio ambiente, quanto do ponto de vista das garantias de inclusão social, como também como agentes do desenvolvimento (ROUSSEFF, 2012).

Aqui, no entanto, fica claro que a natureza da mulher não está ligada apenas a condicionalidades com relação à própria vida das mulheres: está também diretamente conectada com o desenvolvimento do país. A nação, como uma instância macro do lar liderado pelas mulheres, precisa que estas cumpram seus papeis "naturalmente" designados para o bem comum, seja com relação à proteção do meio ambiente (já que são protetoras), ou com relação ao desenvolvimento (já que são esforçadas e trabalhadoras). O objetivo final das políticas gênero-inclusivas seria, portanto, reconhecer que a "natureza" cuidadora da mulher pode ser beneficial e utilizar dessa natureza como instrumento para o desenvolvimento do país - não apenas em termos de inclusão social, ou de proteção ambiental, mas também com relação à economia. $\mathrm{O}$ desenvolvimento não figura como algo que pode ser beneficial à vida das mulheres, mas as mulheres passam a figurar como um potencial benefício para o desenvolvimento:

Em sua relação com o meio ambiente as mulheres têm se destacado como aliadas nas mudanças nos padrões de consumo, no uso de energia, no uso da água e do solo. São guardiãs de conhecimentos tradicionais, mas também são capazes de disseminar avançadas práticas sustentáveis (ROUSSEFF, 2012).

Voltando para o pronunciamento de dia das mulheres, um terceiro trecho relevante diz: "É assim que nós, mulheres, gostamos de cuidar das coisas: vendo todos os detalhes, tintim por tintim" (ROUSSEFF, 2012). Aqui, "nós, mulheres" temos algo em comum, que nos permite que sejamos "nós"; e nós gostamos de cuidar das coisas de uma determinada maneira. Assim como é mãe, e na condição de mãe é um pilar forte, "a mulher" também gosta de cuidar das coisas de forma detalhada. "A mulher" é, repetidas vezes, definida como alguém que cuida de coisas, e esse cuidado é primeiramente intenso (já que a mãe é um pilar que ergue aqueles ao seu redor), e em segundo lugar meticuloso, já que nós mulheres somos muito detalhistas em nossos cuidados.

O quarto trecho desse pronunciamento que destacaremos aqui diz: "Em todo o mundo a voz da mulher se sobressai na defesa da paz, do amor e da justiça" (ROUSSEFF, 2012). Então, como uma mãe que é forte, a voz "da mulher" também se sobressai em determinados assuntos: a paz, o amor e a justiça. "A mulher”, que já foi estabelecida como naturalmente 
mãe e, portanto, pilar da família, possui como aspiração política aqueles valores que empreende em sua própria casa. Então “a mulher" ultrapassa a esfera doméstica, mas nem tanto. "A mulher" cuida do planeta como se fosse seu lar.

O quinto trecho é o seguinte:

Porque você, minha irmã, é quem mais sente na pele as deficiências do serviço público: quando leva seu filho ao hospital, você vê como está o atendimento de saúde; você acompanha a escola do seu filho; você vê no supermercado se o preço da comida está subindo; você sente medo nas ruas escuras, quando volta do trabalho sozinha, sem segurança (ROUSSEFF, 2012).

Aí, vemos reproduzidos os deveres da mulher, que é naturalmente mãe. A mãe é quem leva seu filho ao hospital, a mãe é quem acompanha a escola de seu filho, a mãe é quem faz compras no supermercado.

Podemos ressaltar, aqui, a tensão entre a representação da realidade de uma determinada maneira e o reforço da realidade da maneira como está. Existe uma tendência, socialmente construída, que mulheres cumpram as tarefas descritas no trecho acima. Cabe, então, descrever a realidade dessa maneira, já que é assim que muitas vezes ela funciona. Contudo, o próprio caráter socialmente construído dessa tendência faz com que cada repetição da figura da mulher associada a esses predicados específicos, de forma inquestionada, reforce a obrigação atribuída às mulheres de realizarem essas tarefas, já que isso passa a ser associado com uma suposta naturezada mulher e, portanto, da mãe - natureza esta já evocada no mesmo contexto. Constata-se uma realidade onde mulheres fazem essas tarefas, passando-se também a impressão de que elas devem realiza-las, já que isso faria parte de uma suposta natureza da qual todas as mulheres partilhariam.

O que aprendemos, até então, sobre a mulher como sujeito, é o seguinte: i) que existe algo que permite que se possa retratar essa mulher como um sujeito único, como "mulher" e não mulheres, como defendemos na seção anterior; ii) que esses atributos específicos que as mulheres supostamente partilhariam dizem respeito a seu papel na esfera doméstica, orientado pela sua qualidade de mãe; iii) que essa qualidade de mãe é evocada como o determinante natural do gênero, algo indissociável da existência de uma mulher, que é "naturalmente fonte de vida".

Paralelamente a isso, o contexto nacional conservador dá conta, também, de invisibilizar questões relativas à sexualidade feminina. Essa invisibilização acontece não apenas através do tabu em torno desses assuntos, nos quais se toca bem raramente por parte 
do governo federal, como através da construção narrativa de uma mulher que corresponde a um estereótipo de esposa e mãe heterossexual, monogâmica. Quanto mais se reforça esse tipo de imagem, mais abjetas se tornam manifestações do contrário. Além disso, ao abordar "questões de gênero", quando se refere exclusivamente a mulheres (em oposição às relações de poder que estabelecem o gênero e as hierarquias relativas à sua existência), cristaliza-se um binário onde só existem homens e mulheres - por sua vez definidas por sua natureza, e que estão em uma posição de vítima que se torna estática, já que são as mulheres os objetos de políticas igualitárias e não as relações de poder.

Ao longo dos objetos analisados por este trabalho, encontramos menção à homofobia uma vez, na Assembleia Geral da ONU de 2014, e à violência contra a população LGBT como um todo apenas na cerimônia de sanção da lei contra o feminicídio, em 2015, ambas já no contexto da reeleição. $\mathrm{Na}$ Assembleia da $\mathrm{ONU}$, foi dito que:

$\mathrm{O}$ mesmo empenho que temos em combater a violência contra as mulheres e os negros, os afrobrasileiros, temos também contra a homofobia. A Suprema Corte do meu país reconheceu a união estável entre pessoas do mesmo sexo, assegurandolhes todos os direitos civis, daí decorrentes. Acreditamos firmemente na dignidade de todo ser humano e na universalidade de seus direitos fundamentais. Estes devem ser protegidos de toda seletividade e de toda politização tanto no plano interno como no plano internacional (ROUSSEFF, 2014).

E na ocasião da sanção da lei sobre feminicídio:

Essa morte pelo fato de ser mulher, ela torna a questão de gênero no Brasil, a questão de gênero e da questão do gênero feminino no Brasil, uma questão específica e especial junto com outras categorias, como a questão de morte por ser negro, de discriminação por ser negro, como também toda a violência contra a população LGBT (ROUSSEFF, 2015).

Ambas as ocasiões reconhecem que existe uma conexão entre a violência contra mulheres e a violência contra a população LGBT, assim como o racismo, mas essas conexões não são nunca explicitadas, sempre deixadas nas entrelinhas.O que esses tipos de violência têm em comum é que decorrem, em diferentes medidas, das mesmas normas de gênero.

As normas de gênero que definem quem é a mulher são, também, responsáveis pelas restrições legislativas das mulheres brasileiras com relação a seus direitos sexuais e reprodutivos. Esses direitos, através de nossos objetos de estudo, são sempre entendidos como relativos à maternidade biológica - o direito de ter uma saúde pública que dê conta de um prénatal apropriado, bem como um parto e cuidado de recém-nascidos - ou então ao cuidado de doenças como o câncer de mama. No entanto, a legislação brasileira só permite aborto em 
casos restritos de estupro, feto anencefálico e risco de morte para a mãe, tornando o aborto ilegal - quase sempre inseguro - uma das principais causas de morte materna no Brasil (MINISTÉRIO DA SAÚDE, 2009). Essa é uma questão de saúde pública e no entanto, segue sendo sumariamente ignorada no discurso brasileiro que analisamos. Não há espaço para mulheres que abortem, por qualquer motivo que seja, em um discurso que constitui uma mulher simbólica que é mãe biológica, cuidadora, que coloca sua família acima de tudo. Uma mulher que aborte é incompatível com essa ideia, definida por ser boa; logo, uma mulher que aborte é um ser repreensível.

Tendo estabelecido quem é "a mulher" da qual se fala e quem são as pessoas reais das quais não falamos - e as violências às quais estão sujeitas devido à sua invisibilização seguiremos na próxima seção para analisar quais são as narrativas sobre o papel das mulheres em um contexto mais amplo do âmbito político-econômico, onde encontraremos marcadas influências do paradigma predominante no cenário internacional de mulheres no desenvolvimento.

\section{O Lugar das Mulheres no Sistema}

Falamos, até agora, na construção narrativa de uma natureza comum às mulheres. No entanto, ao longo dos objetos que selecionamos, observamos diversas instâncias que podem parecer contraditórias com relação a essa natureza. No pronunciamento presidencial no fórum de mulheres líderes, por exemplo, observamos um trecho que reconhece diversas particularidades contextuais de diferentes mulheres - que são tratadas, nesse contexto, como mulheres em oposição à mulher:

Trabalhamos em prol das mulheres da cidade, do campo, da floresta, do sertão. De trabalhadoras urbanas, agricultoras, indígenas, quilombolas, ribeirinhas e extrativistas. De líderes políticas, de empresárias, enfim, de todas as mulheres que ousam e que vão, sistematicamente, levantando sua cabeça e entrando no mundo do trabalho, na sociedade como agentes e como sujeito e, sobretudo, eu queria aqui enfatizar, como líderes, como as mulheres aqui presentes, a qual eu faço uma especial homenagem (ROUSSEFF, 2012).

Nesse trecho, mulheres de diferentes locais e profissões são separadas e têm suas diferenças reconhecidas. No entanto, a despeito das singularidades destacadas, ainda é possível que se faça generalizações grosseiras sobre mulheres e seu papel comum na sociedade, até no mesmo pronunciamento, sem que isso pareça estranho. Por quê? 
A despeito da pressuposição de uma suposta natureza da qual todas as mulheres partilham, a perspectiva women in development, que também podemos localizar nas estruturas narrativas que estamos analisando, estabelece que as vidas de mulheres são marcadas por diferentes dificuldades e impedimentos - sobretudo falta de oportunidades e embarreiramento de sua participação no mercado de trabalho e na política. Isso as torna, de certa forma, únicas em suas dificuldades de vida, mas apenas de forma superficial, já que todas são igualmente humanas.

A aplicação do humanismo ao contexto do feminismo, que acontece dentro da vertente liberal que orienta a abordagem WID, estabelece um projeto ético que determina uma essência comum a todos os seres humanos. Comum à humanidade é a racionalidade sobre a qual se baseia o Eu, e para a plena realização humana, é preciso que todos tenham acesso às condições básicas para que se mantenha uma vida digna, da qual todos são merecedores por causa mesmo de sua condição humana. Mas quem, exatamente, é esse sujeito racional? A apropriação da tradição filosófica humanista pelo feminismo político resulta na pressuposição básica de que o sujeito plenamente realizado (ou ao menos que está o mais próximo possível da realização plena) é o Ocidental, e o que possibilita isso é seu contexto político e social, que a partir disso torna-se o padrão do que é positivo e correto. Assim, por causa das condições de vida de mulheres Ocidentais serem melhores, isso significa que o próprio modo de vida Ocidental é o correto, já que permite que mulheres atinjam sua dignidade como seres humanos - a essência humana é a mesma, a cultura funciona como um impedimento à plena realização da dignidade, um atraso. Cultura, nesse caso, significa todos os modos de vida que não são correspondentes ao modo de vida Ocidental, que seria apenas o modo padrão de como se deve viver e que outros povos estão caminhando para alcançar.

Como todos os humanos possuem uma essência comum, portanto, seus objetivos também seriam os mesmos - relativos a "progresso". Então, se todas as mulheres possuem a mesma substância, que é a substância humana, sua necessidade universal é o reconhecimento de sua paridade com homens em termos de seu lugar na sociedade. Esse lugar na sociedade, por sua vez, é ditado sobretudo pelo elemento do trabalho e da participação política.

No trecho do qual falamos no início desta seção, encontramos convergência com essas tendências teóricas. Apesar do reconhecimento das particularidades contextuais que permeiam a vida de tantas mulheres brasileiras, elas ainda são colocadas como se partilhassem de uma essência comum, que orienta objetivos comuns. O principal elemento que liga todas essas 
mulheres, nesse caso, é o trabalho - que, por sua vez, faz com que o objetivo comum entre essas mulheres seja a "inserção" no mercado. As mulheres da cidade são trabalhadoras urbanas; do campo, agricultoras; da floresta, trabalhadoras indígenas, quilombolas, ribeirinhas ou extrativistas. As mulheres que são políticas trabalham em prol das outras trabalhadoras, que assim se inserem na sociedade.

É necessário notar as problemáticas que surgem no que se refere a algumas dessas mulheres, por exemplo as indígenas, como trabalhadoras, já que o modo de produção e economia indígenas são radicalmente diferentes dos modos capitalistas. Em segundo lugar, observamos que a ideia de "inserção" é fundamental na abordagem WID, que pressupõe que o objetivo final do desenvolvimento e das políticas de gênero é a inserção das mulheres em processos já pré-existentes, se amparando na aplicabilidade universal de um modelo específico neoliberal, baseado em uma ideia de sujeito ocidentalista. As mulheres devem ser fagocitadas por um sistema que, em um balanço geral, é benéfico a todos.

Acreditem, como eu acredito, que a participação é o melhor caminho para mudar o país. Participem da vida do seu bairro, da sua cidade, do seu estado e da sua nação. Se mobilizem. Já disse que este é o século das mulheres, mas não é o século das mulheres contra os homens, é o século da mulher trabalhando ao lado do homem, de igual para igual, batalhando com fé e amor por sua família e por seu país (ROUSSEFF, 2012).

Os objetivos para as mulheres não podem ser muito ousados e não desafiam o modelo político nem econômico, visando predominante a participação, ou seja, inserção; é necessário deixar estabelecido que o lugar social dos homens não estará ameaçado por causa das mulheres e que sua vida continuará a mesma, já que o objetivo das mulheres é apenas trabalhar ao lado dos homens; e o papel social das mulheres continuará bastante parecido, também, já que sua inserção econômica e sua batalha continuam voltadas para a manutenção da família e do lar que representa o país.

A suma importância do acesso como base para a igualdade é encontrada no seguinte trecho: "Aqui, a palavra chave para todos é acesso, mas, sobretudo, para a mulher: acesso a recursos naturais em especial à água, acesso ao alimento, acesso à moradia digna, acesso ao saneamento básico, à energia e educação" (ROUSSEFF, 2012).Aqui reflete-se a abordagem WID novamente: é preciso que as mulheres, bem como todos os humanos, possuam acesso a todas as necessidades básicas para que então, através do trabalho, ascendam socialmente. Elas precisam disso por causa de sua essência humana, e porque têm muito a oferecer para o "crescimento" nacional e para a manutenção do sistema econômico. Algumas das críticas a 
essa abordagem mais relevantes para este trabalho dizem respeito à insensibilidade que esta traz em relação a aspectos da desigualdade de gênero que são mais sutis do que bloqueios em acesso às coisas, que por sua vez vêm a impedir a participação plena das mulheres na economia, e à necessidade subsequente de práticas que vêm de baixo para cima (ver SHARMA, 2008). Novamente, as necessidades básicas vêm como forma de garantir que mulheres possam participar mais ainda de esforços econômicos.

A ideia do acesso se estende para a política na medida em que o ponto central sobre a importância do gênero nessa esfera diz respeito à maior participação das mulheres em cargos: "Minha chegada à Presidência significou um momento único de afirmação da mulher na sociedade brasileira" (ROUSSEFF, 2012). Essa necessidade é trazida à luz diversas vezes ao longo dos nossos objetos de estudo e é também um traço que marca a perspectiva women in development. Como mulheres foram barradas ao longo da história no acesso à política, então, o acesso que possuem agora seria uma marca central do progresso em direção à igualdade de gênero. Novamente, a desigualdade é atribuída à falta de acesso a alguma coisa, e não a todo um sistema que é fundamentado na perpetuação de desigualdades de gênero; o acesso das mulheres à política seria uma forma de dar suporte à maior "inclusão" das mulheres na economia capitalista: "A preocupação com a consolidação da presença das mulheres na política deve nortear as iniciativas ligadas a cada um dos pilares do desenvolvimento sustentável: o econômico, o social e o ambiental" (ROUSSEFF, 2012).

Seguindo na questão da inserção, no pronunciamento de dia das mulheres lemos que: "A mulher é um ser empreendedor, precisa, portanto, de oportunidades. A mulher é uma pessoa, antes de tudo, dedicada e trabalhadora, precisa, portanto, de emprego e de capacitação para o trabalho" (ROUSSEFF, 2012). O que temos aqui é, em primeiro lugar, a utilização da suposta natureza da mulher, já previamente construída, para justificar uma mudança no seu status econômico. Porque a mulher é um ser empreendedor, uma pessoa dedicada e trabalhadora (e isso podemos atestar devido ao papel que realiza dentro da família), ela precisa de trabalho formalmente reconhecido pela economia, o emprego, ou acesso a isso através da capacitação.

Ainda dentro da questão econômica, no pronunciamento do fórum de mulheres líderes é dito que:

A autonomia econômica das mulheres, particularmente afetada nessa conjuntura de crise global, é fundamental para a construção de sua cidadania plena. Para tanto, precisamos enfrentar lutas antigas, mas ainda necessárias, em especial, 
pelo igual acesso a oportunidades de trabalho, remuneração e proteção social, e, muitas vezes, por defesa física contra a violência. $\mathrm{O}$ empreendedorismo das mulheres deve ser facilitado por instrumentos de crédito, assistência técnica e propriedade, e protegido da desordem avassaladora das crises financeiras, que precarizam direitos e querem fazer voltar atrás a roda da História, e pela falta da esperança e de perspectiva (ROUSSEFF, 2012).

A "cidadania plena" das mulheres depende de sua situação econômica; partilhando de um traço comum ao paradigma women in development, ao longo de nossos objetos de estudo a perspectiva econômica toma precedência sobre diversos outros temas com relação à situação das mulheres. Evoca-se também a ideia de cidadania, a despeito de essa mesma cidadania seguir sendo construída com base em estereótipos de mulher. Pressupõe-se que, sendo a economia e o trabalho os maiores impedimentos à igualdade das mulheres com relação aos homens, seguidos do acesso a cargos políticos, basta que se derrubem essas barreiras para que haja plena igualdade de gênero. Mesmo a violência contra mulheres vem como um anexo da situação econômica. É estabelecida, então, uma relação profunda entre a economia e a igualdade de gênero (da forma que é entendida, como a igualdade entre homens e mulheres que compõem a família nuclear tradicional): sem a economia, não há igualdade de gênero; sem igualdade de gênero, não funciona a economia. O sistema capitalista passa, então, a ser enxergado como a grande via de emancipação das mulheres (ou "da mulher").

\section{Conclusões}

A chegada de uma mulher na presidência brasileira em 2011 trouxe consigo a celebração de uma nova conquista para as mulheres, especialmente devido à renovada atenção que passou a ser concedida para a questão da mulher na sociedade brasileira. No entanto, ao tentar entender alguns dos pressupostos sobre os quais o discurso presidencial vem se amparando, percebemos que a atenção às mulheres acompanha o reforço de normas de gênero e uma ideia de desenvolvimento baseada em concepções neoliberais.

O reforço das normas de gênero se vê presente na forma através da qual a mulher como sujeito é construída; na definição de quem são as mulheres às quais se referem discursos e políticas públicas. A mulher é caracterizada, ao longo do discurso aqui analisado, pelas imagens de mãe biológica, esposa, heterossexual, pilar da família, um ser que cuida e nutre. Todos esses predicados são constantemente conectados à uma suposta natureza da qual todas as mulheres partilhariam. Essas imagens são fruto de um contexto histórico e sociocultural conservador, com profundas influências religiosas, e através de sua evocação, o construto do 
gênero feminino é (re)produzido, influenciando as ideias de verdade que se têm sobre os corpos e perpetuando o status quo da hierarquia entre diferentes formas de gêneros. Os corolários dessa definição da mulher como um ser que é tal coisa, bem como da família como uma entidade heterossexual, monogâmica, entre homem e mulher - é responsável por (re)forçar o caráter abjeto às manifestações do contrário. A partir disso, surge o contexto de profunda violência de gênero dentro do qual vivemos.

Nos nossos objetos, pudemos estabelecer a influência exercida pelo paradigma internacional de women in development no contexto brasileiro. Essa abordagem se baseia predominantemente na ideia de que é necessária a inclusão das mulheres nos processos de desenvolvimento capitalistas para que estes sejam cada vez mais benéficos tanto ao país quanto às próprias mulheres, e também se ampara em ideais humanistas. Esses ideais, por sua vez, partem do pressuposto que todos os humanos possuem uma essência comum e que, portanto, merecem padrões mínimos de vida e certas garantias, como os direitos humanos.

A mulher, então, merece certos padrões em sua vida (como por exemplo o direito de ser uma "cidadã completa", que contribui para a economia e o crescimento e portanto merece o acesso a hospitais, comida e certos direitos) por partilhar da essência universal do que é o ser humano. No entanto, a mulher é também definida por uma natureza que é particular a ela e que, para que seja a ela particular, precisa então se opor à natureza do homem determinando a necessidade de que ela se ocupe de tarefas familiares e domésticas. No entanto, para a manutenção do sistema vigente é também necessário que alguém realize tarefas domésticas, já que o sistema tem como base unidades familiares. Assim, existe uma espécie de ânsia econômica para que a mulher saia de casa, que se contrasta com a ânsia conservadora para que fique, e com a necessidade que alguém seja responsável por cuidar do lar e das crianças. Nesse contexto, não há espaço algum para que se pense em pessoas LGBT, já que tanto a moralidade cristã, quanto as tradições culturais e as necessidades econômicas determinam que é mais vantajoso que essas pessoas se mantenham invisíveis.

Através de diversos mecanismos retóricos, esses interesses são combinados para estabelecer um discurso que perpetua, respectivamente, a hierarquia de gênero vigente e pressupostos desenvolvimentistas neoliberais, sendo que os segundos dependem do primeiro para existir dessa maneira. Nesse sentido, a imagem singular d"“A mulher" passa a ser um mecanismo de direcionamento e controle das mulheres, que se tornam peças políticas em confrontos culturais, sociais, políticos, econômicos. 
CADERNOS DE RELAÇÕES INTERNACIONAIS, v.11, n.2, 2017. 


\section{BIBLIOGRAFIA}

BUTLER, Judith (1998). "Performative Acts and Gender Constitution: an Essay in Phenomenology and Feminist Theory". Theatre Journal 40 (4): 519-531.

. Bodies That Matter: On the Discursive Limits of Sex. Nova York: Routledge, 1993.

. Gender Trouble: Feminism and the Subversion of Identity. Nova York: Routledge, 2010(1990). Undoing Gender. Nova York: Routledge, 2004.

DATASENADO. DataSenado Ouve Mulheres Sobre Violência Doméstica Contra a Mulher, 2013. Disponível em:

$<$ http://www.senado.gov.br/senado/datasenado/pdf/datasenado/DataSenado-PesquisaViolencia_Domestica_contra_a_Mulher_2013.pdf> Acesso em: 22/06/2015.

FÓRUM BRASILEIRO DE SEGURANÇA PÚBLICA. $7^{\circ}$ Anuário Brasileiro de

Segurança

Pública, 2013.

Disponível em:

〈http://www.forumseguranca.org.br/storage/download//anuario_2013-corrigido.pdf> Acessado em: 22/06/2015.

GRIFFIN, Penny. Gendering the World Bank: Neoliberalism and the Gendered Foundations of Global Governance. Londres: Palgrave Macmillan, 2009.

IPEA. Violência Contra a Mulher: Feminicídios no Brasil, 2013. Disponível em: $<$ http://www.ipea.gov.br/portal/images/stories/PDFs/130925_sum_estudo_feminicidio _leilagarcia.pdf> Acesso em: 22/06/2015.

JABRI, Vivienne (2004). "Feminist Ethics and Hegemonic Global Politics". Alternatives: Global, Local, Political29: 265-284. 
KAPOOR, Ilan. The Postcolonial Politics of Development. Nova York: Routledge, 2008 .

MINISTÉRIO DA SAÚDE, Brasil. 20 Anos de Pesquisas Sobre Aborto no Brasil.Brasília: Ministério da Saúde, 2009.

MOHANTY, Chandra (1984). "Under Western Eyes: Feminist Scolarship and Colonial Discourses”, Boundary 212 (3): 333-358.

NUSSBAUM, Martha. "Human Capabilities, Female Human Beings". In: NUSSBAUM, Martha; GLOVER, John. (Eds.) Women, Culture and Development: A Study of Human Capabilities. Oxford: Clarendon Press, 1995.

O’BRIEN, R., Robert et al. Contesting Global Governance: Multilateral Economic Institutions and Global Social Movements. Nova York: Cambridge University Press, 2003.

PAPART, Janeet al. Theoretical Perspectives on Gender and Development. Ottawa: International Development Research Center, 2000.

PETERSON, Spike (1999). "Sexing Political Identities/Nationalism as Heterosexism". International Feminist Journal of Politics1 (1): 34-65.

ROUSSEFF, Dilma. Discurso da presidenta da República, Dilma Rousseff, durante cerimônia de sanção da lei de tipificação do feminicídio, 2015. Disponível em: $<$ http://www2.planalto.gov.br/acompanhe-o-planalto/discursos/discursos-dapresidenta/discurso-da-presidenta-da-republica-dilma-rousseff-durante-cerimonia-de\%E2\%80\%A61/7>. Acesso em: 10/10/2015. 
. Discurso da Presidenta da República, Dilma Rousseff, na abertura do Debate

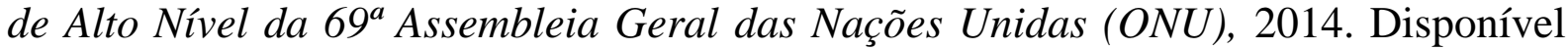
em: $\quad \quad$ http://www2.planalto.gov.br/acompanhe-o-planalto/discursos/discursos-dapresidenta/discurso-da-presidenta-da-republica-dilma-rousseff-na-abertura-do-debatede-alto-nivel-da-69a-assembleia-geral-das-nacoes-unidas-onu $>$ Acesso em: $10 / 10 / 2015$.

. Pronunciamento à Nação da Presidenta da República, Dilma Rousseff, em cadeia nacional de rádio e TV, por ocasião do Dia Internacional da Mulher, 2012. Disponível em: $\quad$ http://www2.planalto.gov.br/acompanhe-oplanalto/discursos/discursos-da-presidenta/pronunciamento-a-nacao-da-presidenta-da$\underline{\text { republica-dilma-rousseff-em-cadeia-nacional-de-radio-e-tv-por-ocasiao-do-dia- }}$ internacional-da-mulher> Acesso em: 10/10/2015.

- Discurso da Presidenta da República, Dilma Rousseff, durante o fórum de mulheres líderes sobre igualdade de gênero e empoderamento das mulheres no desenvolvimento sustentável, $2013 . \quad$ Disponível em: <http://www2.planalto.gov.br/acompanhe-o-planalto/discursos/discursos-dapresidenta/discurso-da-presidenta-da-republica-dilma-rousseff-durante-forum-demulheres-lideres-sobre-igualdade-de-genero-e-empoderamento-das-mulheres-nodesenvolvimento-sustentavel-rio-de-janeiro-rj> Acesso em: 10/10/2015.

SDH/PR, Brasil. Relatório Sobre Violência Homofóbica no Brasil: Ano de 2012, 2013. Disponível em: <http://www.sdh.gov.br/assuntos/lgbt/pdf/relatorio-violenciahomofobica-ano-2012> Acesso em: 22/06/2015.

SEN, Gita; GROWN, Caren. Development, Crises, and Alternative Visions. Nova York: Monthly Review Press, 1987.

SHARMA, Aradhana. Logics of Empowerment: Development, Gender, and Governance in Neoliberal India. Minneapolis: University of Minnesota Press, 2008. 